\title{
Is preparation for end of life associated with pre-death grief in caregivers of people with dementia?
}

\author{
Kirsten J. Moore, ${ }^{1}$ (i) Sophie Crawley, ${ }^{1}$ Victoria Vickerstaff, ${ }^{1}$ Claudia Cooper, ${ }^{2,3}$ \\ Michael King, ${ }^{2}$ and Elizabeth L. Sampson ${ }^{1,4}$ \\ ${ }^{1}$ Marie Curie Palliative Care Research Department, Division of Psychiatry, UCL, London W1T 7NF, UK \\ ${ }^{2}$ Division of Psychiatry, UCL, London W1T 7NF, UK \\ ${ }^{3}$ Camden and Islington NHS Foundation Trust, St. Pancras Hospital, London NW1 OPE, UK \\ ${ }^{4}$ Barnet, Enfield and Haringey Mental Health Trust, St Ann's Hospital, London N15 3TH, UK
}

Objectives: Family caregivers of people with dementia can experience loss and grief before death. We hypothesized that modifiable factors indicating preparation for end of life are associated with lower pre-death grief in caregivers.

Design: Cross-sectional.

Setting: Caregivers of people with dementia living at home or in a care home.

Participants: In total, 150 caregivers, $77 \%$ female, mean age $63.0(\mathrm{SD}=12.1)$. Participants cared for people with mild $(25 \%)$, moderate $(43 \%)$, or severe dementia $(32 \%)$.

\begin{abstract}
Measurements: Primary outcome: Marwit-Meuser Caregiver Grief Inventory Short Form (MMCGI-SF). We included five factors reflecting preparation for end of life: (1) knowledge of dementia, (2) social support, (3) feeling supported by healthcare providers, (4) formalized end of life documents, and (5) end-of-life discussions with the person with dementia. We used multiple regression to assess associations between pre-death grief and preparation for end of life while controlling for confounders. We repeated this analysis with MMCGI-SF subscales ("personal sacrifice burden"; "heartfelt sadness"; "worry and felt isolation").

Results: Only one hypothesized factor (reduced social support) was strongly associated with higher grief intensity along with the confounders of female gender, spouse, or adult child relationship type and reduced relationship closeness. In exploratory analyses of MMCGI-SF subscales, one additional hypothesized factor was statistically significant; higher dementia knowledge was associated with lower "heartfelt sadness."

Conclusion: We found limited support for our hypothesis. Future research may benefit from exploring strategies for enhancing caregivers' social support and networks as well as the effectiveness of educational interventions about the progression of dementia (ClinicalTrials.gov ID: NCT03332979).
\end{abstract}

Key Words: caregivers, pre-death grief, dementia, death preparedness, social support, end of life care, advance care planning, health literacy

\section{Introduction}

Dementia is the seventh leading cause of death worldwide (World Health Organization, 2017), and between 2000 and 2017, the age standardized death rate for dementia more than doubled in the US (Kramarow and Tejada-Vera, 2019). Family and friends, referred to as caregivers, provide the bulk of support to people with dementia and

Correspondence should be addressed to: Kirsten Moore, Marie Curie Palliative Care Research Department, 6th Floor, Maple House, 149 Tottenham Court Road, London W1T 7NF. Phone + 44 2076799488. Email: kirsten.moore@ucl .ac.uk. Received 19 Dec 2019; revision requested 17 Jan 2020; revised version received 04 Feb 2020; accepted 11 Feb 2020. First published online 03 April 2020 are estimated to be equivalent to a workforce of 40 million full-time employees worldwide (Wimo et al., 2018). While caregivers often become proxy decision makers at end of life for a person with dementia (Harrison Dening et al., 2016), evidence suggests the majority do not recognize dementia as a disease you can die from (van der Steen et al., 2013).

Providing care to a family member with dementia can significantly affect the psychological well-being of caregivers (Abreu et al., 2018; Cuijpers, 2005). Grief is often felt before the death of a friend or relative with dementia, as a response to serial losses associated with dementia including the person with dementia's reduced insight, communication, and recognition of the caregiver (Blandin and Pepin, 2017). 
Caregivers may feel that changes in the person with dementia are so profound they are no longer the person they have previously known, thus triggering a process of grief. The process of placing someone with dementia in a care home or nursing home can be a significant loss and intensely distressing for caregivers (Afram et al., 2014; Moore and Dow, 2015). A concept analysis by Lindauer and Harvath (2014) defined pre-death grief as:

\footnotetext{
... the caregiver's emotional and physical response to the perceived losses in a valued care recipient. Family caregivers experience a variety of emotions (e.g. sorrow, anger, yearning and acceptance) that can wax and wane over the course of a dementing disease, from diagnosis to the end of life.
}

It is distinguished from anticipatory grief as it relates to losses already experienced, not only to anticipation of loss (Blandin and Pepin, 2017; Lindauer and Harvath, 2014). Between $47 \%$ and $71 \%$ of family caregivers of people with dementia experience predeath grief (Chan et al., 2013). Higher pre-death grief is associated with complicated grief after death (Romero et al., 2014), so emotional support for grief during care rather than solely after the death may be beneficial (Schulz et al., 2003). Complicated grief or prolonged grief disorder refers to severe, longerterm, maladaptive forms of grief which may impact around one in ten bereaved persons and is considered a disorder requiring further research to be included in the Diagnostic and Statistical Manual of Mental Disorders (Prigerson et al., 2008). Here we acknowledge that pre-death grief is not complicated grief; however, some people may experience intense and long-term (more than 6 or 12 months) pre-death grief which may be more consistent with complicated grief.

Meuser and Marwit developed a Stage Sensitive model of pre-death grief in dementia which ascribes loss to either the caregiver (e.g. reduced employment), the person with dementia (e.g. memory loss and taking part in activities), or to loss of the relationship (e.g. reduced conversation and companionship) (Meuser and Marwit, 2001). The focus of loss differs between adult children and spouses and alters as dementia progresses. The authors used this model to develop the Marwit-Meuser Caregiver Grief Inventory (MMCGI) to assess pre-death grief (Marwit and Meuser, 2002); later revised to a short form [MMCGI-SF (Marwit and Meuser, 2005)]. The tool contains three subscales: "personal sacrifice burden"; "heartfelt sadness and longing"; and "worry and felt isolation."

Preparation for end of life has been closely tied to grief and has medical, psychosocial, spiritual, and practical components (Hebert et al., 2006b; 2008), including having a named person to make decisions, knowing what to expect from the terminal condition, and having finances in place (Steinhauser et al., 2001). Good communication with healthcare providers to discuss prognosis, treatments, cultural, spiritual, and practical issues and managing family conflict is critical (Hebert et al., 2006b).

Not being preparation for end of life is associated with higher levels of complicated grief in bereavement (Barry et al., 2002; Hebert et al., 2006a; Schulz et al., 2015) but has not been explored in the context of pre-death grief. We aimed to examine the relationship between pre-death grief in caregivers of people with dementia and how well caregivers are prepared for that death. Using the MMGCI-SF as the primary outcome, we tested the hypothesis that factors indicating preparation for end of life are associated with lower pre-death grief in caregivers of people with dementia. Secondary aims were to explore other demographic factors associated with pre-death grief and whether there were different associated factors for the three subscales of the MMCGI-SF.

As there are currently no validated tools that measure death preparedness among caregivers of people with dementia (Durepos et al., 2019), we identified five factors that reflected the broad components of preparation for end of life. To help inform development of interventions, we focused on factors that are potentially modifiable. Our first factor reflected understanding of what to expect from the terminal condition (dementia) (Steinhauser et al., 2001). Caregivers who feel well supported by and have good relationships with their family feel better able to prepare for end of life (Breen et al., 2018); therefore, we included a measure of social support. Having a good relationship with healthcare providers (Hebert et al., 2006b) enables caregivers to ask questions about dementia progression. Being engaged in advance care planning has been associated with high preparation for end of life (Barry et al., 2002; Hebert et al., 2006a; Schulz et al., 2015); therefore, we included having any formal documents about end of life care as our fourth factor. Family members often become proxy decision makers and may regret not having had discussions with the person in the earlier stages of dementia (Hirschman et al., 2008) so we included having discussed end-of-life matters with the person with dementia as our fifth factor.

\section{Methods}

We undertook a cross-sectional study of family caregivers of people with dementia living in England and Wales.

\section{Ethical approval}

Ethics approval was obtained through the London South East Research Ethics Committee (Reference 
17/LO/1881) and the University College London Research Ethics Committee (Reference 11755/001). The study was approved by the Health Research Authority (Sponsor Reference Number 17/0477). Participants provided written informed consent.

\section{Eligibility}

Eligible caregivers provided practical, social, emotional, or supervisory support to a friend or family member with a formal diagnosis of any dementiarelated disease. Caregivers were aged 18 and over and lived in England or Wales. The person they cared for could live at home or in a care home. We included caregivers whether or not they were the primary caregiver. We also allowed more than one caregiver in a family to participate as we felt that the experience of grief and loss would be different even within the same family unit. Caregivers who were not able to communicate in English or who did not have capacity to provide informed consent were excluded.

\section{Recruitment}

Participants were recruited through various avenues. The study was included on the National Institute for Health Research (NIHR) Clinical Research Network Portfolio. Nine healthcare services (including mental health, community and hospital services within geographic catchments: 4XLondon, 3XSouth Eastern England, 1XWelsh, and 1XNorthern England) identified caregivers to participate in the study. Sites identified caregivers known to their service either via memory services, Admiral Nursing services (specialist dementia care nurses in the UK), community mental health services, or previous research.

We also recruited through the Join Dementia Research (JDR) website (www.joindementiaresearch .nihr.ac.uk/). JDR is a self-registration service that enables volunteers to register their interest in taking part in dementia research. The register had approximately 39,000 registered volunteers during study recruitment. JDR searches were conducted using postcode radiuses to identify volunteers spread across England and Wales. We contacted matched volunteers to invite them to take part. The study was also promoted by the Alzheimer's Society (UK), Admiral Nursing services, and on the research team's website. Participant assessments occurred from January 2018 to January 2019.

We ensured caregivers had a minimum of three days to consider the Participant Information Sheet before agreeing verbally to take part. We booked in a face to face assessment and sent them a paper copy of the Health Literacy Questionnaire (HLQ) (Osborne et al., 2013) to complete before the interview to reduce the length of the interview.

\section{Data collection}

We collected the HLQ of caregivers and completed a case report form with structured questionnaires and open and closed questions that we estimated would take between one and a half to two hours to complete. The questionnaires included the MMCGI-SF (Marwit and Meuser, 2005), our primary outcome, along with our indicators of preparation for end of life (described below). We also used the Clinical Dementia Rating (Morris, 1993), the Duke University Religion Index (Koenig and Büssing, 2010), Hospital Anxiety and Depression Scale (Zigmond and Snaith, 1983), and the Relationship Closeness Scale (Whitlatch et al., 2001). See Table 1 for the measures recorded.

\section{Indicators of preparation for end of life}

We operationalized our five factors indicating preparation for end of life as follows (additional details on the scales are in Table 1):

1. Knowledge of dementia: total score Dementia Knowledge Assessment Scale (Annear et al., 2015)

2. Good social support - total score from the Social Support subscale of the HLQ (HLQ4)

3. Good relationship with healthcare providers - total score from the "Feeling understood and supported by healthcare providers" subscale of the HLQ (HLQ1)

4. Formalized documents: We asked caregivers "Is there any formally written documents about endof-life care?" Binary response (yes compared with no/do not know)

5. Knowledge of end-of-life preferences of the person with dementia: We asked caregivers "Have you had discussions with the person with dementia regarding their wishes at the end of life?" Binary response (yes/no).

\section{Analysis}

Participant characteristics were summarized using mean (standard deviation), median (interquartile range), and proportions as appropriate. Univariate linear regression analyses were used to explore the predictors for preparation for end of life on pre-death grief, measured using the MMCGI-SF, our primary outcome. The five factors considered in the univariate linear regression were listed above. To test our primary hypothesis, we used multiple regression analysis to explore the impact of the combination of the five factors on MMCGI-SF. The model also included potential confounders: (1) age of the person with dementia; (2) relationship type: (three categories: spouse/partner, adult child, or another relationship); (3) caregiver's gender; (4) care home status (living at home or in a care home); (5) deprivation (as measured by Townsend Deprivation Index 
Table 1. Interview schedule

\begin{tabular}{|c|c|c|}
\hline MEASURE & DESCRIPTION & ANALYSIS \\
\hline $\begin{array}{l}\text { Clinical Dementia Rating } \\
\quad \text { (Morris, 1993) }\end{array}$ & $\begin{array}{l}\text { Dementia severity based on memory, } \\
\text { orientation, judgment and problem } \\
\text { solving, community affairs, home and } \\
\text { hobbies, and personal care. Possible } \\
\text { scores: } 0 \text { (no dementia), } 0.5 \\
\text { (questionable), } 1 \text { (mild), } 2 \text { (moderate), } \\
3 \text { (severe) }\end{array}$ & $\begin{array}{l}\text { We combined } 0.5 \text { and } 1 \text { to form a } \\
\text { "mild" group and compared with } \\
\text { moderate and severe }\end{array}$ \\
\hline $\begin{array}{l}\text { Dementia Knowledge Assessment } \\
\text { Scale (DKAS) (Annear et al., } \\
\text { 2015) }\end{array}$ & $\begin{array}{l}25 \text { statements rated as true, probably true, } \\
\text { probably false, false, or don't know; } 2 \\
\text { points scored for correct statements; } 1 \\
\text { point for a "probably" true or "probably" } \\
\text { false correct response; no points for } \\
\text { incorrect responses. Scores range } 0-50 \\
\text { with a higher score indicating better } \\
\text { knowledge. }\end{array}$ & We used the DKAS total score \\
\hline $\begin{array}{l}\text { Duke University Religion Index } \\
\text { (Koenig and Büssing, 2010) }\end{array}$ & $\begin{array}{l}\text { Five items creating three subscales: } \\
\text { Organizational religious activity (one item } \\
\text { scored 1-6); nonorganizational religious } \\
\text { activity (one item scored 1-6); intrinsic } \\
\text { religiosity (three items each scored } 1-5- \\
\text { total score } 3-15 \text { ). Higher scores indicate } \\
\text { higher religiosity. }\end{array}$ & $\begin{array}{l}\text { We used the item subscale "Intrinsic } \\
\text { religiosity" and dichotomized it } \\
\text { into scores of } 3 \text { "definitely not } \\
\text { true" compared with scores } 4-15 \\
\text { indicating religiosity }\end{array}$ \\
\hline $\begin{array}{l}\text { Health Literacy Questionnaire } \\
\text { (HLQ) (Osborne et al., 2013) }\end{array}$ & $\begin{array}{l}\text { We used two of the nine subscales. Both } \\
\text { were from part } 1 \text { with an average score } \\
\text { range of } 1-4 \text {. Higher scores indicate areas } \\
\text { of strength. We used the subscales: } \\
\text { 1. Feeling understood and supported by } \\
\text { healthcare providers (HLQ1) } \\
\text { 2. Social support for health (HLQ4) }\end{array}$ & $\begin{array}{l}\text { We used average scores from the two } \\
\text { subscales }\end{array}$ \\
\hline $\begin{array}{l}\text { Hospital Anxiety and Depression } \\
\text { Scale (Zigmond and Snaith, } \\
\text { 1983) }\end{array}$ & $\begin{array}{l}14 \text { item instrument: } 7 \text { items relating to } \\
\text { depression and } 7 \text { items relating to anxiety. } \\
\text { Separate scores for anxiety and depression } \\
\text { range from } 0 \text { to } 21 \text { with higher scores } \\
\text { indicating poorer mental health. }\end{array}$ & $\begin{array}{l}\text { We used scores of } 8 \text { and above to } \\
\text { indicate caseness for anxiety or } \\
\text { depression (Zigmond and Snaith, } \\
\text { 1983) }\end{array}$ \\
\hline $\begin{array}{l}\text { Marwit-Meuser Caregiver Grief } \\
\text { Inventory Short Form (MMCGI- } \\
\text { SF) (Marwit and Meuser, 2005) }\end{array}$ & $\begin{array}{l}18 \text { item instrument with } 3 \mathrm{X} 6 \text { item subscales: } \\
\text { 1. personal sacrifice burden; } 2 \text {. heartfelt } \\
\text { sadness and longing; and 3. worry and felt } \\
\text { isolation. Score range: } 18-90 \text {; subscales: } \\
\text { 6-30. Higher scores indicate higher grief } \\
\text { severity. }\end{array}$ & $\begin{array}{l}\text { We used the total score as the } \\
\text { primary outcome measure and } \\
\text { subscales for exploratory analyses }\end{array}$ \\
\hline $\begin{array}{l}\text { Relationship Closeness Scale } \\
\text { (Whitlatch et al., 2001) }\end{array}$ & $\begin{array}{l}\text { Six items with a score range of } 4-24 \text { with a } \\
\text { higher score indicating a closer } \\
\text { relationship. Using an approach previously } \\
\text { used by Fauth et al. }(2012) \text {, we asked } \\
\text { participants to complete this twice (1) } \\
\text { reflecting on relationship before dementia } \\
\text { and (2) at the time of the interview. }\end{array}$ & $\begin{array}{l}\text { We subtracted the pre-dementia } \\
\text { score from the current score to } \\
\text { create a change score ranging } \\
\text { from }-20 \text { to } 20 \text { with a negative } \\
\text { score indicating a decline in } \\
\text { closeness since dementia. }\end{array}$ \\
\hline
\end{tabular}


of having at least 10 participants per variable. For knowledge of end-of-life preferences and deprivation, we had missing data for one participant. We imputed these missing data points using mean imputation.

Finally, we undertook exploratory analyses by repeating the above regression analysis with each of the three subscales of the MMCGI-SF. The subscales measure different aspects of grief with two incorporating burden and stress and one reflecting loss and sadness. This exploratory analysis examined whether different factors were more or less associated with the different components of pre-death grief. Regression analyses were conducted using Stata statistical software, version 15.

\section{Results}

\section{Description of participants}

We interviewed 150 participants $(62 \%)$ of a total 242 referred to the research team or who expressed interest in the study. Of the 92 people who did not participate, $22(24 \%)$ were ineligible mainly due to the death of the person with dementia or no formal dementia diagnosis. Twelve $(13 \%)$ were unable to be contacted by the research team, and $58(63 \%)$ were eligible but refused or were unable to take part (e.g. unable to find the time, ill-health in the family, lack of suitable interview venue, did not respond to follow-up calls). Only three caregivers refused due to concerns about the distressing nature of the study. Although we asked health services to record the number of caregivers they approached, we were not able to obtain this data and therefore are unable to define the sampling frame and response rate. Participants were recruited via memory/mental health services (48\%), JDR (39\%), and newsletters and general study promotion (13\%).

A description of participants is presented in Table 2. A third of participants were females caring for their male partner, $13 \%$ were males caring for their wife, and one caregiver was caring for his male partner (data not in shown). A further third of participants were women caring for mothers, $7 \%$ women caring for fathers, $6 \%$ men caring for their mother, and $2 \%$ men caring for their father. There were four pairs of related participants (a husband caring for his wife whose daughter also participated, two pairs of daughters caring for their parent whose own daughter also participated [granddaughter of person with dementia], and one pair of sisters caring for a parent).

Table 2 shows mean MMCGI-SF scores for various factors included in our regression model as well as depression and anxiety.
Multiple regression analysis - total grief score

From the multiple regression model (see Table 3), only one of the five hypothesized indicators of preparation for end of life was significantly associated with total grief at the 5\% significance level: HLQ social support subscale (coef $-6.95,95 \%$ CI $(-10.22,-3.68) ; p<0.001)$. This finding shows that higher social support was associated with lower total grief. There was some evidence of a negative association between pre-death grief and dementia knowledge (DKAS), but this was not statistically significant $(p=0.086)$.

Three confounders were also significantly associated with higher grief at the $5 \%$ significance level: younger age of the person with dementia (coef $-0.25,95 \%$ CI $(-0.46,-0.04) ; p=0.018)$; greater decline in relationship closeness (coef $-0.80,95 \%$ CI $(-1.22,-0.39) ; p<0.001)$; and being a female caregiver (coef $5.18,95 \% \mathrm{CI}$ $(1.10,9.25) ; p=0.013)$.

The final model of independent variables most associated with pre-death grief is shown in Table 4. Social support was the only hypothesized factor with a significant association. $R^{2}$ for this model was $37.5 \%$ indicating that over a third of the variation in the outcome was explained by these four variables. In this final model, we can still see that social support, gender, and change in closeness remain strongly associated with total grief. However, now relationship with the person with dementia instead of age of person with dementia is associated with total grief.

\section{Multiple regression analysis - grief subscales}

We repeated the regression analysis for each of the MMCGI-SF subscales. Results after backward elimination are reported in Table 5 (initial model not shown). Of our hypothesized factors, social support was associated with "personal sacrifice and burden" and "worry and felt isolation," while dementia knowledge was associated with "heartfelt sadness and longing."

\section{Discussion}

We found limited support for our hypothesis with only one of our five modifiable factors indicating preparation for end of life (social support), being associated with severity of pre-death grief. This resonates with the finding that home palliative care services may lead to improved end-of-life care outcomes for the patient, but do not help alleviate caregiver grief (Gomes et al., 2013). Our only hypothesized factor significantly associated with higher pre-death grief was poorer social 
Table 2. Demographic profile

\begin{tabular}{|c|c|c|}
\hline CATEGORICAL VARIABLES & $N(\%)$ & MEAN MMCGI-SF (SD) \\
\hline All participants & $150(100)$ & $57.6(12.8)$ \\
\hline \multicolumn{3}{|l|}{ Gender of caregiver } \\
\hline Female & $116(77.3)$ & $59.1(12.8)$ \\
\hline Male & $34(22.7)$ & $52.6(11.6)$ \\
\hline \multicolumn{3}{|l|}{ Gender of person with dementia } \\
\hline Female & $82(54.7)$ & $55.0(11.7)$ \\
\hline Male & $68(45.3)$ & $60.8(13.4)$ \\
\hline \multicolumn{3}{|l|}{ Relationship with person with dementia } \\
\hline Spouse & $70(46.7)$ & $59.5(12.5)$ \\
\hline Adult child & $72(48.0)$ & $57.2(12.8)$ \\
\hline Other ${ }^{\mathrm{a}}$ & $8(5.3)$ & $44.0(6.5)$ \\
\hline \multicolumn{3}{|l|}{ Dementia severity (CDR) } \\
\hline Mild & $38(25.3)$ & $57.7(13.2)$ \\
\hline Moderate & $64(42.7)$ & $57.5(12.4)$ \\
\hline Severe & $48(32.0)$ & $57.6(13.2)$ \\
\hline \multicolumn{3}{|l|}{ Where does person with dementia live? } \\
\hline Live at home with participant caregiver & $72(48.0)$ & $59.3(12.7)$ \\
\hline Lives at home with others/alone & $37(24.7)$ & $55.9(14.0)$ \\
\hline Care home/supported accommodation & $41(27.3)$ & $56.2(11.7)$ \\
\hline \multicolumn{3}{|l|}{ Rurality } \\
\hline Urban Major Conurbation & $70(47.0)$ & $56.0(12.9)$ \\
\hline Urban City and Town & $62(41.6)$ & $58.9(12.8)$ \\
\hline Rural $^{\mathrm{b}}$ & $17(11.4)$ & $59.9(12.8)$ \\
\hline \multicolumn{3}{|c|}{ End-of-life care discussions with person with dementia } \\
\hline No & $62(41.6)$ & $56.9(13.6)$ \\
\hline Yes & $87(58.4)$ & $58.2(12.3)$ \\
\hline \multicolumn{3}{|l|}{ Formalized documents of end-of-life care } \\
\hline No & $79(52.7)$ & $57.6(13.4)$ \\
\hline Not sure & $8(5.3)$ & $48.6(8.8)$ \\
\hline Yes & $63(42.0)$ & $58.7(12.2)$ \\
\hline \multicolumn{3}{|l|}{ Religiosity } \\
\hline 3 & $74(49.3)$ & $59.1(12.3)$ \\
\hline $4-15$ & $76(50.7)$ & $56.1(13.2)$ \\
\hline \multicolumn{3}{|l|}{ Depression and anxiety } \\
\hline Depressive symptoms (HADS $\geq 8$ ) & $44(29.3)$ & $68.2(9.8)$ \\
\hline Anxiety symptoms (HADS $\geq 8$ ) & $78(52.0)$ & $64.3(11.2)$ \\
\hline Numeric variables & \multicolumn{2}{|c|}{ Mean (SD) } \\
\hline Age of caregiver; age of person with dementia & \multicolumn{2}{|c|}{$63.0(12.1) ; 80.3(9.7)$} \\
\hline Dementia knowledge (DKAS score) & \multicolumn{2}{|c|}{$34.8(7.0)$} \\
\hline Social support (HLQ4) & \multicolumn{2}{|c|}{$2.7(0.6)$} \\
\hline Good relationship with providers (HLQ1) & \multicolumn{2}{|c|}{$2.7(0.7)$} \\
\hline Change in closeness & \multicolumn{2}{|c|}{$-3.6(4.4)$} \\
\hline Deprivation & \multicolumn{2}{|c|}{$6.6(2.7)$} \\
\hline
\end{tabular}

Abbreviations: CDR, clinical dementia rating; HADS, hospital anxiety and depression scale; DKAS, dementia knowledge assessment scale; MMCGI-SF, Marwit-Meuser caregiver grief inventory short form; HLQ, health literacy questionnaire; HLQ4, HLQ subscale 4 (social support for health); HLQ1, HLQ subscale 1 (feeling understood and supported by healthcare providers); SD, standard deviation.

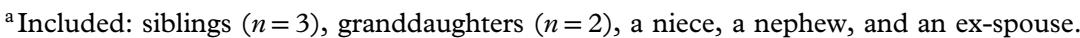

${ }^{\mathrm{b}}$ Includes: Urban City and Town in a sparse setting, Rural Town and Fringe, Rural Village, Rural Hamlets, and Isolated Dwellings.

support. While social support may help caregivers prepare for end of life, it may have a more direct relationship to grief by providing caregivers an emotional outlet to help process their grief. This would be reflective of a public health model that suggests most people adapt and cope with grief through the support from their social network rather than formal or professional services (Aoun et al., 2012).

There was a trend toward better knowledge of dementia being associated with lower levels of predeath grief, and this reached significance in our exploratory analysis for the subscale "heartfelt 
Table 3. Univariate and multiple regression analysis for total MMCGI-SF score

\begin{tabular}{|c|c|c|c|c|}
\hline & \multicolumn{2}{|c|}{ UNIVARIATE ANALYSES } & \multicolumn{2}{|c|}{ MULTIPLE REGRESSION ANALYSES } \\
\hline & COEFFICIENT $(95 \% \mathrm{CI})$ & $P$-VALUE & COEFFICIENT $(95 \% \mathrm{CI})$ & $P$-VALUE \\
\hline \multicolumn{5}{|l|}{ Indicators of preparation for end of life } \\
\hline 1. Dementia knowledge (DKAS score) & $-0.27(-0.57,0.16)$ & 0.064 & $-0.23(-0.49,0.03)$ & 0.086 \\
\hline 2. Social support (HLQ4) & $-10.19(-13.14,-7.25)$ & $<0.001$ & $-6.95(-10.22,-3.68)$ & $<0.001$ \\
\hline $\begin{array}{l}\text { 3. Good relationship with providers } \\
\text { (HLQ1) }\end{array}$ & $-5.85(-8.60,-3.11)$ & $<0.001$ & $-1.36(-4.18,1.47)$ & 0.343 \\
\hline \multicolumn{5}{|l|}{ 4. Formalized documents of EOLC } \\
\hline No or not sure (ref). & 0.00 & & 0.00 & \\
\hline Yes & $1.88(-2.31,6.06)$ & 0.377 & $1.09(-2.91,5.08)$ & 0.591 \\
\hline \multicolumn{5}{|c|}{ 5. EOLC discussions with person $\mathrm{w}$ dementia } \\
\hline No (ref.) & 0.00 & & 0.00 & \\
\hline Yes & $1.26(-2.94,5.46)$ & 0.555 & $0.85(-2.80,4.51)$ & 0.645 \\
\hline \multicolumn{5}{|l|}{ Confounders } \\
\hline \multicolumn{5}{|l|}{ Gender of caregiver } \\
\hline Male (ref). & 0.00 & & 0.00 & \\
\hline Female & $6.43(1.60,11.27)$ & 0.009 & $5.18(1.10,9.25)$ & 0.013 \\
\hline \multicolumn{5}{|l|}{ Where does person with dementia live? } \\
\hline Other location (ref.) & 0.00 & & 0.00 & \\
\hline Live at home & $1.99(-2.64,6.63)$ & 0.397 & $1.79(-2.88,6.45)$ & 0.450 \\
\hline Age of person with dementia & $-0.16(-0.38,0.05)$ & 0.128 & $-0.25(-0.46,-0.04)$ & 0.018 \\
\hline Change in closeness & $-1.05(-1.49,-0.61)$ & $<0.001$ & $-0.80(-1.22,-0.39)$ & $<0.001$ \\
\hline Dementia severity (CDR) & & 0.999 & & 0.8483 \\
\hline Mild (ref) & 0.00 & & 0.00 & \\
\hline Moderate & $-0.13(-5.34,5.09)$ & & $0.54(-3.97,5.06)$ & \\
\hline Severe & $-0.03(-5.34,5.09)$ & & $1.58(-4.04,7.21)$ & \\
\hline \multicolumn{5}{|l|}{ Religiosity } \\
\hline 3 & 0.00 & & 0.00 & \\
\hline $4-15$ & $-2.96(-7.08,1.15)$ & 0.157 & $-0.95(-4.40,2.49)$ & 0.585 \\
\hline Relationship with person with dementia & & 0.004 & & 0.0691 \\
\hline Spouse (ref.) & 0.00 & & 0.00 & \\
\hline Adult child & $-2.31(-6.42,1.81)$ & & $0.54(-3.86,4.95)$ & \\
\hline Other & $-15.53(-24.7,-6.38)$ & & $-8.91(-16.94,-0.89)$ & \\
\hline Deprivation & $-0.27(-1.03,0.49)$ & 0.485 & $-0.43(-1.09,0.24)$ & 0.207 \\
\hline
\end{tabular}

Note: The bold represents $P<0.05$.

Abbreviations: CI, confidence interval; DKAS, dementia knowledge assessment scale; HLQ, health literacy questionnaire; HLQ4, HLQ subscale 4 (social support for health); HLQ1, HLQ subscale 1 (feeling understood and supported by healthcare providers); EOLC, end-of-life care; CDR, clinical dementia rating; ref., reference group.

Table 4. Final model of independent variables most associated with total MMCGI-SF score

\begin{tabular}{|c|c|c|c|}
\hline & COEFFICIENT & $95 \% \mathrm{CI}$ & $P$-VALUE \\
\hline Social support (HLQ4) & -8.46 & $-11.24,-5.68$ & $<0.001$ \\
\hline \multicolumn{4}{|l|}{ Gender of caregiver } \\
\hline Male (ref.) & 0.00 & & \\
\hline Female & 4.71 & $0.66,8.75$ & 0.023 \\
\hline Closeness change & -0.77 & $-1.16,-0.37$ & $<0.001$ \\
\hline \multicolumn{4}{|c|}{ Relationship with person with dementia } \\
\hline Spouse (ref.) & 0.00 & & 0.027 \\
\hline Adult child & -1.32 & $-4.85,2.20$ & \\
\hline Other & -10.63 & $-18.34,-2.92$ & \\
\hline
\end{tabular}

Abbreviations: CI, confidence interval; ref., reference group.

Using backwards elimination at the $5 \%$ level, the factors

were removed in the following order: (1) dementia severity,

(2) knowledge of end-of-life care preferences, (3) religiosity,

(4) live at home, (5) is there any formal last power of attorney or other documents, (6) feeling understood, (7) DKAS score, (8) age of person with dementia. 
sadness and longing." Educational interventions for caregivers of people with dementia are a commonly tested intervention; however, improved knowledge, the direct outcome expected of an educational intervention, is often ignored. Our systematic review of educational interventions on the progression of dementia found only two of eleven studies measured dementia knowledge as an outcome, while all studies measured outcomes of burden and depression (Moore et al., 2019). Given that only 39\% of participants (data not shown) in the current study accurately identified dementia as life shortening, it appears that the availability and effectiveness of caregiver education interventions require review and consideration of health literacy.

Having a good relationship with healthcare providers was associated with pre-death grief in the univariate but not the multiple regression, suggesting intercorrelations of this variable with other predictor variables in the multiple regression. Further investigation is needed in how support from healthcare professionals influences preparation for end of life. We considered dementia severity may impact on quality of relationships, but our measure of relationship with health providers showed similar scores for all levels of dementia severity (no statistical test).

Formally written documents about end-of-life care and knowledge of end-of-life preferences of the person with dementia were not associated with pre-death grief. Mean MMCGI-SF scores were very similar but slightly higher for those who had discussions and formal documents in place - the reverse of our hypothesized direction. This is possibly due to these documents and discussions being more likely to occur in advanced stages of disease (Lamahewa et al., 2017), but dementia severity did not impact on pre-death grief. During interviews we found that when people had discussed end-of-life preferences with the person with dementia, discussions tended to focus on arrangements after death rather than preparing for care before death. These discussions therefore may not help prepare the caregiver for becoming a proxy decision maker as health declines and decisions about treatment come to the fore; a potentially stressful situation for caregivers (Davies et al., 2014).

Despite the potential benefits of end-of-life discussions with caregivers, many people find these topics difficult (Dening et al., 2013; Hirschman et al., 2008). Caregivers struggle to formalize in writing future wishes on behalf of the person with dementia and professionals tend to be reluctant to initiate end-of-life discussions (Almack et al., 2012). It is possible that while caregivers in this study may have had discussions, the discussions may have been upsetting or unhelpful in preparing caregivers for end-of-life care. This could explain the lack of 
relationship with pre-death grief. Developing an Advance Care Plan is difficult in dementia and further research needs to inform how plans can be practically implemented to have positive impacts for people with dementia and their caregivers (Harrison Dening et al., 2011).

Other nonmodifiable factors in our model were shown to be associated with pre-death grief. Females experienced higher levels of pre-death grief than males and may have implications for how interventions are targeted and delivered. Relationship type was also found to be significant. Mean MMCGI-SF scores show only a small difference between spouses and adult children; however, those who had seconddegree relationships such as granddaughter, niece, or sibling reported much lower levels of pre-death grief possibly due to lower familial closeness. Unsurprisingly, those who reported greater declines in the closeness of their relationship since dementia also experienced higher levels of pre-death grief. Older age of the person with dementia was associated with lower pre-death grief for the subscales: "heartfelt sadness and longing"; and "worry and felt isolation." It was also significant in the initial regression of the total grief score but not after backward elimination. Clinicians should be aware that some characteristics will put caregivers at greater risk of higher pre-death grief. The MMCGI-SF may be a useful method for identifying caregivers needing emotional support for pre-death grief.

Caregivers in our study had an average MMCGISF score of 58. A score of 54 and above shows that on average caregivers somewhat agree with all 18 indicators of grief suggesting a high level of grief and potentially the need for increased support. To date there has not been a MMCGI-SF cutoff identified to indicate those in need of additional support for grief.

\section{Strengths and limitations}

We were able to recruit our target sample size to enable power to test our hypothesis. We aimed to recruit a sample of caregiver's representative of those caring for a person with dementia in the UK. The demographic features of our sample appear similar to the broader caregiver population providing support for a representative population. However, relying on clinical teams and JDR for recruitment may have led to some bias. Clinicians may have focused on recruiting caregivers who were experiencing higher levels of grief as this was the topic of the study; conversely, they may have avoided asking caregivers who they felt were struggling with grief. We did, however, have caregivers with high and low/ no grief, which is important for a regression analysis to examine associated factors.
As there is currently no suitable tool to measure preparedness for the death among caregivers of people with dementia (Durepos et al., 2019), we selected variables that were consistent with the literature on common domains reflecting preparation for end of life. We chose variables that were potentially modifiable to guide development of interventions to support caregivers to prepare for end of life and adjust to predeath grief. However, our factors may not provide a good indication of preparation for end of life. Some studies have simply asked people whether or not they feel prepared (Hebert et al., 2006a) given there may be individual variation in how people judge whether they are prepared. For descriptive purposes, we asked caregivers whether they felt emotionally and practically prepared for end of life; however, we did not include these questions in the model as we felt that this would not be helpful in informing interventions. The development of a validated tool to assess death preparedness reliably was in progress during this study (Durepos et al., 2019) and will help to advance research in this area.

Another limitation is that we did not adjust for Type 1 errors due to the exploratory nature of the analysis. As a cross-sectional study, we are unable to infer directionality or causality. For example, we are unable to determine whether social support helps reduce grief, or lower grief helps carers maintain their social network.

\section{Conclusion}

While previous research has shown a relationship between preparation for end of life and post-death complicated grief, this is the first study to explore this relationship in pre-death grief. We found limited support for our hypothesis that modifiable factors indicating preparation for end of life are associated with lower pre-death grief in caregivers of people with dementia. It is still important, however, to help caregivers prepare for end of life. Future research should examine whether preparing caregivers for end of life can be achieved while also helping them cope with grief and loss. Services and future research should explore strategies for enhancing caregivers' social support and networks to reduce pre-death grief and promote effective educational interventions about the progression of dementia.

\section{Acknowledgments}

We would like to thank the caregivers who took time to participate in this study and the services and JDR that supported recruitment. We would also like to thank Dr Marilyn Relf, Dr Karen Harrison-Dening, 
Dr Nathan Davies, Associate Professor Briony Dow and members of the Expert by Experience panel who provided guidance and advice on this study.

\section{Conflict of interest}

None.

\section{Source of funding}

This work was supported by a Fellowship from the Alzheimer's Society, UK (grant number 325: ASSF-16-004) to KJM and SC; Marie Curie core grant (grant number MCCC-FCO-16-U) to ELS and VV; National Institute for Health Research Biomedical Research Centre and Camden and Islington National Health Service Foundation Trust to CC. The authors have not entered into an agreement with the funding organization that has limited their ability to complete the research as planned and published the results. The authors have had full control of all the primary data, and the authors are willing to allow the journal to review their data if requested.

\section{Description of authors' roles}

The study was designed and conceived by KJM, VV, CC, MK, and ELS. Recruitment of participants and data collection were undertaken by SC and KJM. Statistical analysis was overseen by VV, and analysis was undertaken by VV, KJM, and SC. The manuscript was prepared by KJM and critically reviewed and approved by all authors.

\section{References}

Abreu, W., Tolson, D., Jackson, G. A. and Costa, N. (2018). A cross-sectional study of family caregiver burden and psychological distress linked to frailty and functional dependency of a relative with advanced dementia. Dementia, 19, 301-318. doi: 10.1177/1471301218773842.

Afram, B., Verbeek, H., Bleijlevens, M. H. and Hamers, J. P. (2014). Needs of informal caregivers during transition from home towards institutional care in dementia: a systematic review of qualitative studies. International Psychogeriatrics, 1-12. doi: 10.1017/s1041610214002154.

Almack, K., Cox, K., Moghaddam, N., Pollock, K. and Seymour, J. (2012). After you: conversations between patients and healthcare professionals in planning for end of life care. BMC Palliative Care, 11, 15. doi: 10.1186/1472684x-11-15.

Annear, M. J. et al. (2015). Dementia knowledge assessment scale: development and preliminary psychometric properties. Fournal of the American Geriatrics Society, 63, 2375-2381. doi: 10.1111/jgs.13707.
Aoun, S.M., Breen, L. J., O'Connor, M., Rumbold, B. and Nordstrom, C. (2012). A public health approach to bereavement support services in palliative care. Australian and New Zealand Fournal of Public Health, 36, 14-16. doi: 10 $.1111 /$ j.1753-6405.2012.00825.x.

Barry, L. C., Kasl, S. V. and Prigerson, H. G. (2002). Psychiatric disorders among bereaved persons: the role of perceived circumstances of death and preparedness for death. The American fournal of Geriatric Psychiatry, 10, 447-457. doi: 10.1097/00019442-200207000-00011.

Blandin, K. and Pepin, R. (2017). Dementia grief: a theoretical model of a unique grief experience. Dementia, 16, 67-78. doi: 10.1177/1471301215581081.

Breen, L. J., Aoun, S. M., O'Connor, M., Howting, D. and Halkett, G. K. B. (2018). Family caregivers' preparations for death: a qualitative analysis. Fournal of Pain and Symptom Management, 55, 1473-1479. doi: 10 .1016/j.jpainsymman.2018.02.018.

Chan, D., Livingston, G., Jones, L. and Sampson, E. L. (2013). Grief reactions in dementia carers: a systematic review. International fournal of Geriatric Psychiatry, 28, 1-17. doi: 10.1002/gps.3795.

Cuijpers, P. (2005). Depressive disorders in caregivers of dementia patients: a systematic review. Aging and Mental Health, 9, 325-330. doi: 10.1080/13607860500090078.

Davies, N., Maio, L., Rait, G. and Iliffe, S. (2014). Quality end-of-life care for dementia: what have family carers told us so far? A narrative synthesis. Palliative Medicine, 28, 919-930. doi: 10.1177/0269216314526766.

Dening, K., Jones, L. and Sampson, E. L. (2013). Preferences for end-of-life care: a nominal group study of people with dementia and their family carers. Palliative Medicine, 27, 409-17. doi: 10.1177/0269216312464094.

Durepos, P., Ploeg, J., Akhtar-Danesh, N., Sussman, T., Orr, E. and Kaasalainen, S. (2019). Caregiver preparedness for death in dementia: an evaluation of existing tools. Aging and Mental Health, 1-10. doi: 10.1080/ 13607863.2019.1622074.

Fauth, E. et al. (2012). Caregivers' relationship closeness with the person with dementia predicts both positive and negative outcomes for caregivers' physical health and psychological well-being. Aging and Mental Health, 16, 699-711. doi: 10.1080/13607863.2012.678482.

Gomes, B., Calanzani, N., Curiale, V., McCrone, P. and Higginson, I. J. (2013). Effectiveness and costeffectiveness of home palliative care services for adults with advanced illness and their caregivers. Cochrane Database of Systematic Reviews, 6, Cd007760. doi: 10.1002/14651858 .CD007760.pub2.

Harrison Dening, K., Jones, L. and Sampson, E. L. (2011). Advance care planning for people with dementia: a review. International Psychogeriatrics, 23, 1535-1551. doi: 10.1017/s1041610211001608.

Harrison Dening, K., King, M., Jones, L., Vickestaff, V. and Sampson, E. L. (2016). Advance care planning in dementia: do family carers know the treatment preferences of people with early dementia? PLoS ONE, 11, e0159056. doi: 10.1371/journal.pone.0159056.

Hebert, R. S., Dang, Q. and Schulz, R. (2006a). Preparedness for the death of a loved one and mental health in bereaved caregivers of patients with dementia: findings 
from the REACH study. Fournal of Palliative Medicine, 9, 683-693. doi: 10.1089/jpm.2006.9.683.

Hebert, R. S., Prigerson, H. G., Schulz, R. and Arnold, R. M. (2006b). Preparing caregivers for the death of a loved one: a theoretical framework and suggestions for future research. Fournal of Palliative Medicine, 9, 1164-1171. doi: 10.1089/jpm.2006.9.1164.

Hebert, R. S., Schulz, R., Copeland, V. and Arnold, R. M. (2008). What questions do family caregivers want to discuss with health care providers in order to prepare for the death of a loved one? An ethnographic study of caregivers of patients at end of life. Fournal of Palliative Medicine, 11, 476-483. doi: 10 $.1089 /$ jpm.2007.0165.

Hirschman, K. B., Kapo, J. M. and Karlawish, J. H. (2008). Identifying the factors that facilitate or hinder advance planning by persons with dementia. Alzheimer Disease and Associated Disorders, 22, 293-298. doi: 10.1097/ WAD.0b013e318169d669.

Koenig, H. G. and Büssing, A. (2010). The Duke University Religion Index (DUREL): a five-item measure for use in epidemological studies. Religions, 1, 78-85. doi: 10.3390/rel1010078.

Kramarow, E. A. and Tejada-Vera, B. (2019). Dementia mortality in the United States, 2000-2017. National Vital Statistics Reports, 68, 1-29.

Lamahewa, K. et al. (2017). A qualitative study exploring the difficulties influencing decision-making at the end-of-life for people with dementia. Health Expectations, 21, 118-127. doi: 10.1111/hex.12593.

Lindauer, A. and Harvath, T. A. (2014). Pre-death grief in the context of dementia caregiving: a concept analysis. Fournal of Advanced Nursing, 70, 2196-2207. doi: 10.1111 /jan.12411.

Marwit, S. J. and Meuser, T. M. (2002). Development and initial validation of an inventory to assess grief in caregivers of persons with Alzheimer's disease. Gerontologist, 42, 751-765. doi: 10.1093/geront/42.6.751.

Marwit, S. J. and Meuser, T. M. (2005). Development of a short form inventory to assess grief in caregivers of dementia patients. Death Studies, 29, 191-205. doi: 10.1080/0748 1180590916335.

Meuser, T. M. and Marwit, S. J. (2001). A comprehensive, stage-sensitive model of grief in dementia caregiving. Gerontologist, 41, 658-670. doi: 10.1093/geront/41.5.658.

Moore, K. J. and Dow, B. (2015). Carers continuing to care after residential care placement. International Psychogeriatrics, 27, 877-880. doi: 10.1017/s1041610 214002774.

Moore, K. J., Lee, C. Y., Sampson, E. L. and Candy, B. (2019). Do interventions that include education on dementia progression improve knowledge, mental health and burden of family carers? A systematic review. Dementia. doi: $10.1177 / 1471301219831530$.
Morris, J. C. (1993). The Clinical Dementia Rating (CDR): current version and scoring rules. Neurology, 43, 2412-2414. doi: 10.1212/wnl.43.11.2412-a.

Osborne, R. H., Batterham, R. W., Elsworth, G. R., Hawkins, M. and Buchbinder, R. (2013). The grounded psychometric development and initial validation of the Health Literacy Questionnaire (HLQ). BMC Public Health, 13, 658. doi: 10.1186/14712458-13-658.

Prigerson, H. G., Vanderwerker, L. C. and Maciejewski, P. K. (2008). A case for inclusion of Prolonged Grief Disorder in DSM-V. In: M.S. Stroebe, R.O. Hansson, H. Schut and W. Stroebe (Eds.), Handbook of Bereavement Research and Practice: Advances in Theory and Intervention (pp. 165-186). Washington, DC: American Psychological Association.

Romero, M. M., Ott, C. H. and Kelber, S. T. (2014). Predictors of grief in bereaved family caregivers of person's with Alzheimer's disease: a prospective study. Death Studies, 38, 395-403. doi: 10.1080/07481187.2013.809031.

Schulz, R., Boerner, K., Klinger, J. and Rosen, J. (2015). Preparedness for death and adjustment to bereavement among caregivers of recently placed nursing home residents. Fournal of Palliative Medicine, 18, 127-133. doi: 10 .1089/jpm.2014.0309.

Schulz, R. et al. (2003). End-of-life care and the effects of bereavement on family caregivers of persons with dementia. The New England fournal of Medicine, 349, 1936-1942. doi: 10.1056/NEJMsa035373.

Steinhauser, K. E. et al. (2001). Preparing for the end of life: preferences of patients, families, physicians, and other care providers. Fournal of Pain and Symptom Management, 22, 727-737. doi: 10.1016/s0885-3924(01)00334-7.

van der Steen, J. T., Onwuteaka-Philipsen, B. D., Knol, D. L., Ribbe, M. W. and Deliens, L. (2013). Caregivers' understanding of dementia predicts patients' comfort at death: a prospective observational study. BMC Medicine, 11, 105. doi: 10.1186/1741-7015-11-105.

Whitlatch, C. J., Schur, D., Noelker, L. S., Ejaz, F. K. and Looman, W. J. (2001). The stress process of family caregiving in institutional settings. Gerontologist, 41, 462-473. doi: 10.1093/geront/41.4.462.

Wimo, A., Gauthier, S., Prince, M., On behalf of ADI's Medical Scientific Advisory Panel and the Alzheimer's Disease International publications team (2018). Global Estimates of Informal Care. London: Alzheimer's Disease International and the Karolinska Institutet.

World Health Organization. (2017). The top 10 causes of death [Online]. Available at: http://www.who.int/mediacentre/ factsheets/fs310/en/; last accessed 10 November 2017.

Zigmond, A. S. and Snaith, R. P. (1983). The hospital anxiety and depression scale. Acta Psychiatrica Scandinavica, 67, 361-370. doi: 10.1111/j.1600-0447.1983.tb09716.x. 